\title{
Endothelin Antagonism in Experimental Hepatic Fibrosis Implications for Endothelin in the Pathogenesis of Wound Healing
}

Don C. Rockey and John J. Chung

Liver Center Laboratory and Department of Medicine, University of California, San Francisco General Hospital, San Francisco, California 94110

\begin{abstract}
The liver's response to chronic injury is fibrosis, which is analogous to wound healing in other organs. Hepatic wounding is characterized by the "activation" of resident stellate cells (lipocytes, Ito cells) to myofibroblast-like cells that produce increased amounts of smooth muscle $\alpha$-actin and extracellular matrix. Stellate cells possess abundant endothelin $(\mathrm{ET})$ receptors $\left(\mathrm{ET}_{\mathrm{A} / \mathrm{B}}\right)$ and, therefore, are subject to the effects of ET-1 and 3. In this study, we investigated whether ETs contribute to the activation of stellate cells and consequently, fibrogenesis. In cultured stellate cells, ET-1 and sarafotoxin $\mathrm{S} 6 \mathrm{C}$ (a potent $\mathrm{ET}_{\mathrm{B}}$ receptor agonist) stimulated stellate cell activation, as assessed by expression of smooth muscle $\alpha$-actin. Furthermore, the mixed $\mathrm{ET}_{\mathrm{A} / \mathrm{B}}$ receptor antagonist, bosentan, blocked this process. Next, we administered bosentan during the induction of liver injury in two mechanistically distinct forms of hepatic wounding. Bosentan reduced levels of type I collagen and cellular fibronectin mRNAs in whole-liver tissue extracts in both models. In freshly isolated stellate cells from injured livers, bosentan reduced expression of activation markers, including smooth muscle $\alpha$-actin and extracellular matrix mRNAs. We further demonstrate that endothelin antagonism after establishment of fibrosing injury reduced stellate cell activation and matrix production. These data indicate that ET contributes to stellate cell activation and fibrogenesis. Because ET is upregulated in diverse forms of parenchymal injury, we speculate that ET may play an important role in the wound-healing response. (J. Clin. Invest. 1996. 98:13811388.) Key words: liver • stellate cell • lipocyte • sarafotoxin - bosentan
\end{abstract}

\section{Introduction}

Liver injury, regardless of etiology, is typified by enhanced extracellular matrix deposition and scarring, which ultimately lead to epithelial dysfunction with attendant clinical sequelae

Portions of this work were presented in abstract form at the 1995 American Association for the Study of Liver Disease meeting, Chicago, IL, 4-7 November 1995.

Address correspondence to Don C. Rockey, M.D., Liver Center Laboratory, Building 40, Room 4102, San Francisco General Hospital, San Francisco, CA 94110. Phone: 415-206-4806/4857; FAX: 415641-0517; E-mail:don@itsa.ucsf.edu

Received for publication 12 January 1996 and accepted in revised form 12 July 1996.

J. Clin. Invest.

(C) The American Society for Clinical Investigation, Inc.

0021-9738/96/09/1381/08 \$2.00

Volume 98, Number 6, September 1996, 1381-1388
(1). A central feature of the response to hepatic injury is the transformation of resident mesenchymal cells termed stellate cells (lipocytes, Ito cells) from a quiescent to an "activated" phenotype (2). The activation process in stellate cells is common to all forms of liver injury and is characterized by a coordinately regulated cascade of events that includes de novo expression of smooth muscle $\alpha$-actin, development of a prominent contractile phenotype, enhanced cellular proliferation, and increased production of extracellular matrix $(2,3)$.

The endothelins (ET-1 ${ }^{1}$, ET-2, ET-3) are a family of potent vasoconstrictive substances whose effects extend beyond vasoregulation (4-6). They have been shown to be potent mitogens for smooth muscle cells, may influence hormone production, and appear to be involved in neural crest development (5-7). The biologic effects of the ETs are variable and depend on tissue and cell-specific expression of ET receptors $(5,6)$. Much of the current understanding about the effects of ETs derives from studies examining the effect of ET antagonists, such as bosentan, a mixed nonpetide receptor antagonist with high specificity and affinity for both $\mathrm{ET}_{\mathrm{A}}$ and $\mathrm{ET}_{\mathrm{B}}$ receptors $(5,6,8,9)$.

Initial liver studies indicated that both ET-1 and ET-3 cause vasoconstriction of the hepatic vasculature and induce glycogenolysis (10). ET receptors are detectable on all major hepatic cell types (hepatocytes, stellate cells, endothelial cells, and Kupffer cells), but are most abundant on stellate cells (1114). These data have raised the possibility that stellate cells are a major target of ET isoforms within the liver. Support for this postulate comes from studies demonstrating that ETs cause contraction of stellate cells, an effect that is mediated by both of the known ET receptors (15). Moreover, stellate cell contractility and activation appear to be linked such that contraction increases in proportion to the degree of activation (16). Recent evidence indicates that circulating levels of ET-1 are elevated in liver injury (17), and that its source appears to be the liver itself as tissue levels of preproET-1 mRNA and immunoreactive ET-1 are increased $(18,19)$. Such data raise the possibility that ETs could have prominent effects on stellate cells during liver injury.

Previous studies indicated that $\mathrm{ET}_{\mathrm{B}}$ receptors outnumber $\mathrm{ET}_{\mathrm{A}}$ receptors on stellate cells, and that both receptors mediate physiologic effects $(14,15)$. This information suggested that antagonism of both receptors would be necessary to inhibit putative effects of ETs on stellate cells. In the current study, we tested the hypothesis that paracrine or autocrine ET in the injured liver not only induces stellate cell contraction, but may contribute to stellate cell activation and, therefore, the fibrogenic response. We tested this possibility by examining whether ETs activate stellate cells in culture and whether the novel mixed $\mathrm{ET}_{\mathrm{A}} / \mathrm{ET}_{\mathrm{B}}$ receptor antagonist bosentan alters this process in vivo in liver injury.

1. Abbreviations used in this paper: ALT, alanine transferase; ET, endothelin. 


\section{Methods}

Animal models of hepatic fibrosis. Hepatic fibrosis was induced in male retired breeder Sprague-Dawley rats $(450-550 \mathrm{~g})$ by intragastric administration of carbon tetrachloride or by bile duct ligation. For all animals receiving carbon tetrachloride, this compound was administered every $5 \mathrm{~d}$ at $0.5 \mathrm{ml} / \mathrm{kg}$. Animal weight was monitored, and the dosage of carbon tetrachloride was adjusted accordingly. Bile duct ligation was performed by identification and ligation of the common bile duct as described (20). Controls received carbon tetrachloride or underwent bile duct ligation on the same schedule as experimental animals.

To exclude the possibility that bosentan acted by blocking induction of injury in the carbon tetrachloride model, we examined parameters of acute injury in animals that were given bosentan $48 \mathrm{~h}$ before a single dose of carbon tetrachloride. Liver histology and aminotransferase levels (alanine aminotransferase [ALT]) were assessed $24 \mathrm{~h}$ after administration of carbon tetrachloride. Plasma ALT values were $1,113 \pm 577 \mathrm{IU} /$ liter and $989 \pm 504(n=4)$ for bosentan-treated and control animals, respectively. The degree of hepatocellular necrosis was no different between the two groups of animals. As a control for bile duct ligation, we also measured bilirubin levels in animals that were undergoing this procedure. We detected no statistically significant differences in total plasma bilirubin (or ALT levels) between control and bosentan-treated animals after bile duct ligation.

Administration of bosentan. For rats in which we tested whether bosentan (8) (4-tert-butyl- $N$-[6-(2-hydroxy-ethoxy)-5-(2methoxy-phenoxy)-2, 2'-bipyrimidin-4-yl]-benzenesulfonamide), a gift from Martine Clozel (Hoffmann-La Roche, Basel, Switzerland), was capable of preventing stellate cell activation, bosentan was begun $2 \mathrm{~d}$ before the initiation of injury. In those receiving carbon tetrachloride, bosentan was mixed with pulverized rat chow and adjusted to deliver $100 \mathrm{mg}$ / $\mathrm{kg}$ per d. For rats undergoing bile duct ligation, bosentan at the same dosage as above, in 5\% gum arabic (Sigma Immunochemicals, St. Louis, MO), was administered by gavage. The dosage of bosentan administered was based on previous in vivo studies in the rat (Clozel, M., personal communication). Control animals received pulverized rat chow or underwent gavage with vehicle alone at the same rate as experimental animals. For animals receiving bosentan before the initiation of liver injury, livers were harvested and cell preparations were performed $5 \mathrm{~d}$ after the final carbon tetrachloride gavage (and on the 8th d after bile duct ligation. Livers from control animals were harvested on the same schedule.

For rats in which injury was established before the initiation of bosentan, bosentan was administered continuously beginning $24 \mathrm{~h}$ after the final (10th) dose of carbon tetrachloride. Livers from experimental and control animals were harvested, and cell preparations were performed $17 \mathrm{~d}$ after the final gavage.

Cell isolation. Stellate cells were isolated by perfusion in situ with pronase and collagenase (both from Boehringer Mannheim, Indianapolis, IN), as previously described (21). The purity of stellate cells was assessed by identification of cells displaying vitamin A autofluorescence and desmin immunoreactivity.

Immediately after isolation, cells were homogenized in guanidinium isothiocyanate or Laemli sample buffer for RNA extraction or immunoblot analysis, respectively. Some cells were suspended in modified medium 199 containing 20\% serum (10\% horse/10\% calf; Flow Laboratories, Inc., McLean, VA), layered on uncoated glass chamber slides (Nunc, Inc., Naperville, IL), and maintained in a moisturized incubator at $37^{\circ} \mathrm{C}$ with $2 \% \mathrm{CO}_{2}$. Cells in which immunocytochemical studies were performed were used within $24 \mathrm{~h}$ after plating.

Immunocytochemistry. Cell cultures were washed with PBS and fixed with methanol $\left(10 \mathrm{~min}\right.$ at $\left.4^{\circ} \mathrm{C}\right)$. Specimens were incubated in PBS containing $0.1 \%$ powdered milk (Carnation, Los Angeles, CA) and $2 \%$ sheep serum (Sigma) for $30 \mathrm{~min}$, washed, and incubated with primary antibody in PBS and $0.1 \%$ milk overnight at $4^{\circ} \mathrm{C}$. Cells were washed, and the primary antibody was detected with fluorescein-con- jugated anti-mouse and/or Texas red-conjugated anti-rabbit secondary antibodies (both from Amersham, Arlington Heights, IL) for $2 \mathrm{~h}$. After washing and mounting, specimens were examined under epifluorescence with a Microphot microscope (Nikon Inc., Instrument Group, Melville, NY). Control specimens were processed identically, except that the first antibodies were nonimmune rabbit Ig and/or an irrelevant $\mathrm{mAb}$.

Fresh liver tissue was snap frozen in liquid nitrogen, sectioned (6- $\mu \mathrm{m}$ sections), fixed in acetone at $-20^{\circ} \mathrm{C}$, and processed in the same manner as cultured cells.

Immunoblot. Fresh cell isolates were lysed in $62.5 \mathrm{mM}$ Tris- $\mathrm{HCl}$ buffer, $\mathrm{pH} 6.8$, containing $1 \%$ SDS, $10 \%$ glycerol, and $2 \% \beta$-mercaptoethanol, and were boiled for $3 \mathrm{~min}$. Samples were separated by SDS-PAGE ( $8.0 \%$ acrylamide) under reducing conditions and transferred to nitrocellulose. Nonspecific binding was blocked by preincubation of the blot in full-strength PBS containing $5 \%$ bovine albumin (Sigma) and 2\% serum (from the same species as the secondary antibody). The nitrocellulose was then incubated with smooth muscle $\alpha$-actin antibody, followed by biotinylated anti-mouse IgG (Amersham) and then by avidin-biotin-linked peroxidase (Vector Laboratories, Burlingame, CA), and was visualized by incubation of the blot with diaminobenzidine (Sigma) and $0.1 \%$ hydrogen peroxide. Bands corresponding to smooth muscle $\alpha$-actin were quantitated by scanning densitometry (Hoefer Scientific Instruments, San Francisco, CA). Rat aorta lysate and cultured hepatic endothelial cells (which do not express smooth muscle $\alpha$-actin) were used as positive and negative controls, respectively (3).

Extraction of total RNA and RNase protection assay. Total RNA was extracted in guanidinium isothiocyanate (22), and the integrity of all samples was documented by visualization of $18 \mathrm{~S}$ and $28 \mathrm{~S}$ ribosomal bands after electrophoresis through a $0.8 \%$ formaldehyde/agarose minigel.

Total RNA was incubated with $0.5-1.0 \times 10^{6}$ Cerenkov cpm of ${ }^{32} \mathrm{P}$-labeled cRNA, denatured at $78^{\circ} \mathrm{C}$, and hybridized in solution for $16 \mathrm{~h}$ at a temperature established as optimal in preliminary experiments (range $=56^{\circ}-70^{\circ} \mathrm{C}$ ). After hybridization, RNase $\mathrm{T} 2$ was added to digest unbound label and unprotected mRNA. The protected hybrids were denatured and separated by electrophoresis through a $5 \%$ polyacrylamide/urea sequencing gel. Dried gels were applied to x-ray film (X-OMat AR-5; Eastman Kodak Co., Rochester, NY) for 12-24 h. Bands corresponding to the protected labeled fragment were quantitated by scanning densitometry (Hoefer Scientific Instruments). Transfer RNA was used as a negative RNA for all experiments.
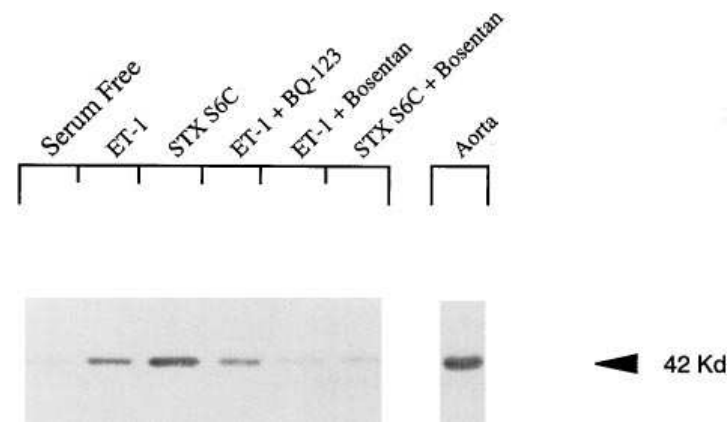

Figure 1. Endothelin-induced stellate cell activation in culture. Stellate cells were isolated from normal animals as described in Methods. After $48 \mathrm{~h}$ in culture, serum-free conditions were introduced, and cells were incubated with ET-1 or sarafotoxin S6C (each $2 \mathrm{nM}$ ) with or without antagonists (bosentan and BQ-123, each $10 \mu \mathrm{M}$ ) for an additional $48 \mathrm{~h}$. Identical quantities of cell protein extract were separated by SDS-PAGE and immunoblotted with anti-smooth muscle $\alpha$-actin antibody, as described in Methods. Smooth muscle $\alpha$-actin is identified at $42 \mathrm{kD}$. Aorta serves as a positive control. $S F$, serum free; $S T X$, sarafotoxin S6C. A representative immunoblot is shown $(n=4)$. 
cDNAs encoding rat $\alpha 1$ (I) collagen, cellular fibronectin (EIIIA or $\mathrm{A}^{+}$fibronectin), and $\mathrm{S}-14$, the latter used as an internal housekeeping mRNA, have been previously described $(23,24)$. Radiolabeled cRNA was generated by transcription with SP6 or T7 polymerase using $\left[\alpha-{ }^{32} \mathrm{P}\right] \mathrm{CTP}(25)$. Specific activity of all radiolabeled transcripts was $\sim 0.5 \times 10^{9} \mathrm{cpm} / \mu \mathrm{g}$.

Histomorphometric quantitation of collagen content and proliferation. Liver specimens were fixed in $10 \%$ neutral buffered formalin. $15-\mu \mathrm{m}$ sections were stained in $0.1 \%$ sirius red F3B in saturated picric acid (both from Sigma), as previously described (26). Collagen surface density was quantitated using a computerized image analysis system (IMAGE 1, Version 4.18; Universal Imaging Co., West Chester, PA) with incorporated imagery card, color monitor, mouse, and laser printer. The surface density of collagen in blinded specimens was measured at a video screen display magnification of $410 \times$ or $160 \times$, and expressed as a percent (the ratio of collagen surface area per total analyzed field surface). The major areas of fibrotic deposits examined were the centrilobular area and portal tract. In each case, the area analyzed extended beyond the central or portal vein into the surrounding lobule. At a low magnification, all the compartments of the liver were analyzed. Variation in individual measurements was tested and determined to be $<10 \%$. The average of the score taken from 10 random fields was used to generate a single score for each animal's liver.

Stellate cells were counted in liver sections probed with antidesmin (Dako Co., Carpenteria, CA) and/or proliferating cell nuclear antigen (PCNA) (Novocastra Lab., UK) antibody. Desmin (stellate cells) and/or PCNA-positive cells were counted in 10 random fields in each region for each liver. The average number of cells counted in specific regions was determined and used as a single data point with which to calculate statistics. Lobular areas refer to noncentral parenchymal regions.

Statistical analysis. Numerical data where statistics are given represent the mean \pm SEM of the individual experiments. Unless stated otherwise, $n$ refers to the number of individual livers examined. Statistical significance for differences between groups was determined by the Wilcoxon or Student's $t$ test.

\section{Results}

For examining the direct effect of ET on stellate cell activation in culture, we used ET-1 and the $\mathrm{ET}_{\mathrm{B}}$ receptor agonist sarafotoxin S6C. Both compounds were stimulatory, as assessed by expression of smooth muscle $\alpha$-actin (Fig. 1), a marker of the activated phenotype (3). The activating effect of both ET-1 and sarafotoxin S6C were inhibited by bosentan (Fig. 1). The pure $\mathrm{ET}_{\mathrm{A}}$ receptor antagonist, BQ-123, was relatively less effective, suggesting a prominent role of the $\mathrm{ET}_{\mathrm{B}}$ receptor in stellate cell activation. BQ-123 had no effect on sarafotoxin S6C-induced activation (not shown). Studies to investigate possible toxic effects of bosentan $(10-20 \mu \mathrm{M})$ on stellate cells demonstrated that bosentan did not affect the ability of stellate
A

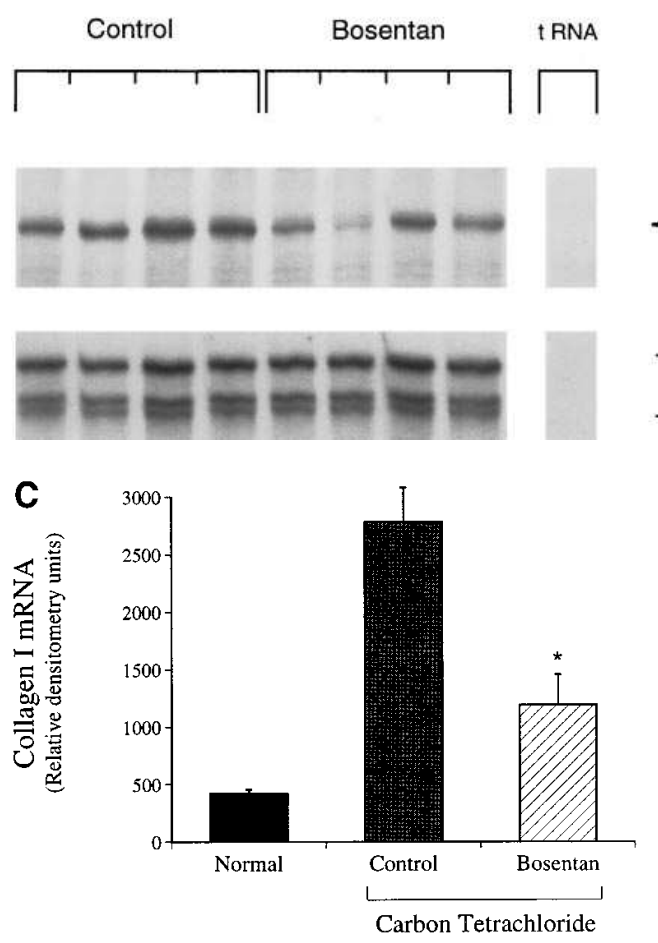

B

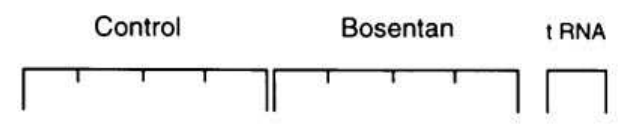

Collagen I
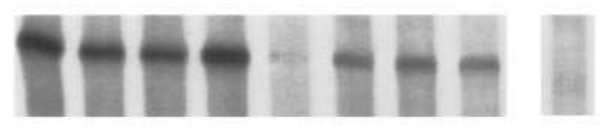

Collagen I
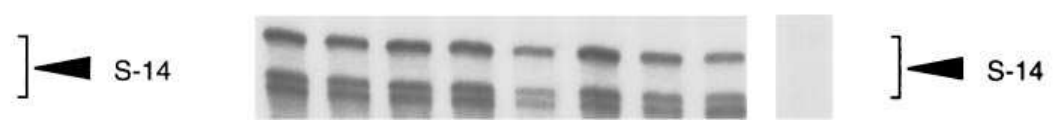

Figure 2. Bosentan reduces type I collagen mRNA expression during hepatic wound healing. Bosentan was administered $2 \mathrm{~d}$ before and during the induction of experimental liver injury, as described in Methods. Livers were harvested $5 \mathrm{~d}$ after the final (fourth) dose of carbon tetrachloride and on the 8th d after bile duct ligation. Total hepatic cellular RNA was isolated and hybridized with radiolabeled cRNA (type I collagen or S-14, the latter a ribosomal internal standard mRNA), as described in Methods. ( $a$ and $b$ ) Representative RNase protection assays of four individual liver specimens probed for type I collagen and S-14 after carbon tetrachloride (10 $\mu \mathrm{g}$ total RNA) and bile duct ligation (10 $\mu \mathrm{g}$ total RNA), respectively. Type I collagen mRNA was measured in normal animals and in two additional sets of specimens from experimental and control groups, scanned, normalized to S-14 expression, and shown graphically: $(c)$ carbon tetrachloride and $(d)$ bile duct ligation. $P<0.005$ for differences between normal and control, and $* P<0.05$ for differences between control and bosentan for each experimental group; $n=6$ for each group. 
Table I. Effect of ET Antagonism on Hepatic Fibrosis (Quantitative Morphometric Analysis of Hepatic Collagen Content by Sirius Red)

\begin{tabular}{lcccccc}
\hline & & \multicolumn{2}{c}{ Carbon tetrachloride } & & \multicolumn{2}{c}{ Bile duct ligation } \\
\cline { 3 - 4 } \cline { 6 - 7 } Area* & Normal & Control & Bosentan & & Control & Bosentan \\
\hline Central & $0.29 \pm 0.04$ & $1.99 \pm 0.19^{\ddagger}$ & $0.54 \pm 0.10^{\S}$ & & $0.49 \pm 0.10$ & $0.35 \pm 0.07$ \\
Portal & $0.80 \pm 0.11$ & $4.80 \pm 0.71^{\ddagger}$ & $1.92 \pm 0.09^{\S}$ & & $3.33 \pm 0.19^{\ddagger}$ & $1.63 \pm 0.23^{\S}$ \\
All & $0.59 \pm 0.12$ & $3.71 \pm 0.59^{\ddagger}$ & $1.46 \pm 0.11^{\S}$ & $2.20 \pm 0.15^{\ddagger}$ & $1.12 \pm 0.14^{\S}$
\end{tabular}

Bosentan was administered in pulverized rat chow or by gavage (100 $\mathrm{mg} / \mathrm{kg}$ per day) beginning 2 days before the initiation of liver injury (carbon tetrachloride given by gavage every $5 \mathrm{~d}$ for four doses or bile duct ligation for $8 \mathrm{~d}$ ). Liver specimens were fixed in $10 \%$ neutral buffered formalin, sections were stained in $0.1 \%$ sirius red F3B, and collagen surface density was quantitated in a blinded fashion using computerized image analysis, as described in Methods. *Central and portal refer to the central vein and the portal tract areas as well as the parenchymal area immediately surrounding these spaces. "All" refers to all hepatic areas, as visualized under low magnification. ${ }^{\ddagger} P<0.001$ for differences between normal and control, and ${ }^{\S} P<0.01$ for differences between control and bosentan, $n=6$ for each experimental injury condition.

cells to exclude propidium iodide $(n=2)$. Furthermore, total protein synthesis after exposure of stellate cells to bosentan $(24 \mathrm{~h})$ was unchanged $(n=2)$.

We next administered bosentan before and during the induction of hepatic injury in two different models of liver injury (a toxic model, recurrent carbon tetrachloride administration; and a cholestatic model, complete biliary obstruction). Since stellate cells are the major effectors of the fibrogenesis during liver injury and our hypothesis was that antagonism of the effect of ET(s) on stellate cells would reduce their activation, we examined whether the putative effects of bosentan on stellate

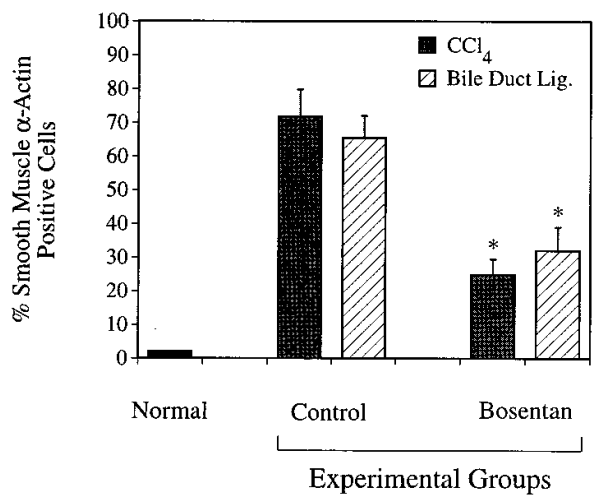

Figure 3. Effect of ET antagonism during liver injury on stellate cell smooth muscle $\alpha$-actin (immunocytochemistry). Experimental liver injury and bosentan administration was induced as described in Fig. 2. Stellate cells were isolated $5 \mathrm{~d}$ after the final dose of carbon tetrachloride (and on the 8th d after bile duct ligation, and they were allowed to adhere on plastic chamber wells overnight. Cells were fixed and subjected to immunocytochemistry with antidesmin and antismooth muscle $\alpha$-actin antibodies. The percentage of cells expressing both desmin and smooth muscle $\alpha$-actin as a proportion of desminpositive cells is shown. $P<0.001$ for differences between normal and control and $* P<0.01$ for differences between normal and control as well as control and bosentan; $n=4$ for each experimental injury condition. cells affected the overall wounding response, as assessed by expression of extracellular matrix constituents in the whole liver. In whole-liver extracts, bosentan reduced the interstitial matrix mRNA, type I collagen, in the livers of animals treated
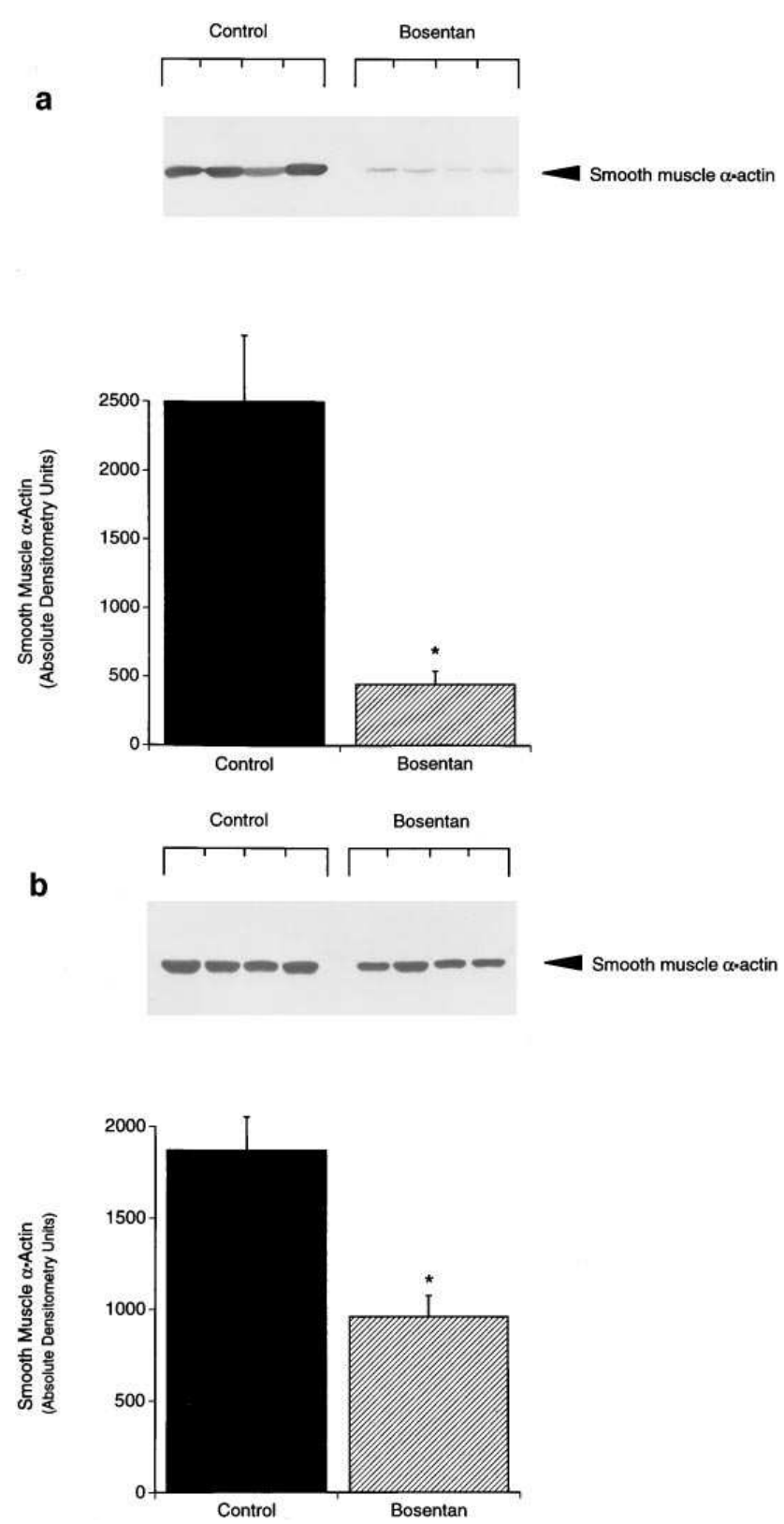

Figure 4. Inhibition of stellate cell activation by ET antagonism (immunoblot). Stellate cells were isolated as described in Fig. 3 and immediately lysed. Identical quantities of total protein were separated by PAGE, and immunoblot with anti-smooth muscle $\alpha$-actin antibody was performed as described in Methods. Representative immunoblots of lysates after carbon tetrachloride $(a)$ and bile duct ligation (b) are shown in the upper portion of each figure. The band for smooth muscle $\alpha$-actin was detected at $42 \mathrm{kD}$. Samples from six different specimens for each condition in each experimental group were quantitated by scanning densitometry, and the data are displayed graphically in the bottom part of each figure. $* P<0.05$ for differences between control and bosentan, $n=6$ for each experimental injury condition. Smooth muscle $\alpha$-actin is not detectable in freshly isolated stellate cells from normal animals (not shown). 
Table II. Effect of Bosentan on Extracellular Matrix mRNA Expression in Stellate Cells during Liver Injury

\begin{tabular}{ccccc}
\hline & Type of Liver Injury & Normal & Control & Bosentan \\
\hline \multirow{2}{*}{ Col I } & Carbon tetrachloride & $0.04 \pm 0.01$ & $1.0 \pm 0.15$ & $0.47 \pm 0.08^{*}$ \\
& Bile duct ligation & $0.05 \pm 0.02$ & $1.0 \pm 0.07$ & $0.45 \pm 0.05^{*}$ \\
& Carbon tetrachloride & - & $1.0 \pm 0.18$ & $0.62 \pm 0.06^{*}$ \\
$\mathrm{cFN}$ & Bile duct ligation & - & $1.0 \pm 0.19$ & $0.58 \pm 0.06^{*}$
\end{tabular}

Bosentan was administered in pulverized rat chow or by gavage (100 $\mathrm{mg} / \mathrm{kg}$ per day) beginning $2 \mathrm{~d}$ before the initiation of liver injury (carbon tetrachloride given by gavage every $5 \mathrm{~d}$ for four doses or bile duct ligation over $8 \mathrm{~d}$ ). Stellate cells were isolated by pronase/collagenase perfusion and ultracentrifugation, as described in Methods. Total RNA was extracted and RNase protection assay was performed using radiolabeled cRNA probes specific for type I collagen, cellular fibronectin, and S-14 (5 $\mu \mathrm{g}$ of total RNA for each). Specific bands were scanned, and signals were normalized to those for S-14. Data are presented as relative values, and the value for control stellate cells was arbitrarily set at 1.0. Cellular fibronectin mRNA was undetectable in normal stellate cells. ${ }^{*} P<0.05$ for control compared to bosentan, $n=6$ for each carbon tetrachloride and bile duct ligation. Col I, type I collagen, cFN, cellular fibronectin.

with carbon tetrachloride or undergoing bile duct ligation by 56 and $46 \%$, respectively (Fig. 2). Similar reductions in expression of cellular fibronectin (a basement membrane type matrix component) mRNA were detected (not shown). During carbon tetrachloride-induced fibrogenesis, histologic analysis revealed collagen and extracellular matrix deposition primarily in central and portal areas in both control and bosentantreated animals. Central-central, central-portal, and portalportal bridging were occasionally present in both groups of animals, but were more prominent in control than in bosentantreated animals. Sirius red quantitative morphometric analysis demonstrated that collagen was reduced in the central and portal areas (proportionally to a slightly greater degree in central

Table III. ET Antagonism in Established Hepatic Fibrosis (Quantitative Morphometric Analysis of Hepatic Collagen Content by Sirius Red)

\begin{tabular}{lrc}
\hline Hepatic Area* & \multicolumn{1}{c}{ Control } & Bosentan \\
\hline Central & $7.17 \pm 1.29$ & $2.99 \pm 0.57^{\ddagger}$ \\
Portal & $13.53 \pm 2.54$ & $5.10 \pm 0.93^{\ddagger}$ \\
All & $9.99 \pm 2.22$ & $4.33 \pm 0.80^{\ddagger}$
\end{tabular}

Liver injury was induced with carbon tetrachloride (given every $5 \mathrm{~d}$ at $0.5 \mathrm{ml} / \mathrm{kg}$ as described in Methods). Bosentan was administered continuously beginning $24 \mathrm{~h}$ after the final (10th) dose of carbon tetrachloride, control and bosentan exposed livers were harvested, and cell preparations were performed $17 \mathrm{~d}$ after the final gavage. Liver specimens were fixed in $10 \%$ neutral buffered formalin, sections were stained in $0.1 \%$ sirius red F3B, and collagen surface density was quantitated in a blinded fashion using computerized image analysis as described in Methods. * "Central" and "portal" refer to the central vein and the portal tract areas, as well as the parenchymal area immediately surrounding these spaces. "All" refers to all hepatic areas, as visualized under low magnification. ${ }^{\ddagger} P<0.01$ for differences between control and bosentan, $n=6$ for each group. than portal areas; Table I). With bile duct ligation, ET antagonism only reduced collagen deposition in the extended portal area (there was no significant increase in collagen in central areas, even in control animals in this model) (Table I).

Stellate cells were isolated from the livers of animals that were undergoing injury, and the effect of ET antagonism was quantitated by measuring smooth muscle $\alpha$-actin and extracellular matrix mRNA expression in individual stellate cell populations. For immunocytochemical analysis, isolates were placed in overnight culture to allow adherence. Bosentan reduced the number of smooth muscle $\alpha$-actin-positive cells by 67 and $51 \%$ in the carbon tetrachloride and bile duct ligation models, respectively (Fig. 3). Immunoblot of freshly isolated cell lysates for smooth muscle $\alpha$-actin demonstrated that bosentan reduced this marker of activation by 82 and $51 \%$, respectively (Fig. 4). Likewise, bosentan decreased type I collagen and cellular fibronectin mRNA levels in stellate cells isolated from injured livers to between 45 and $62 \%$ of control values, respectively (Table II).

A further characteristic of stellate cell activation is enhanced cellular proliferation. In cultured stellate cells, ET can stimulate or inhibit $[3 \mathrm{H}]$ thymidine incorporation (19). To assess cellular proliferation in vivo, stellate cells were quantitated (using desmin and PCNA immunolabeling) in each model of liver injury. For the carbon tetrachloride model of injury, bosentan reduced the number of stellate cells visualized per high powered field (HPF) from 19.3 \pm 1.1 cells/HPF to $13.4 \pm 0.9$, and $22.4 \pm 1.3$ to $17.0 \pm 1.8$ in lobular and fibrous septal ("band") areas. After bile duct ligation, the number of stellate cells was reduced from $22.9 \pm 2.5$ to $14.6 \pm 4.3$, and $70.3 \pm 10.3$ to

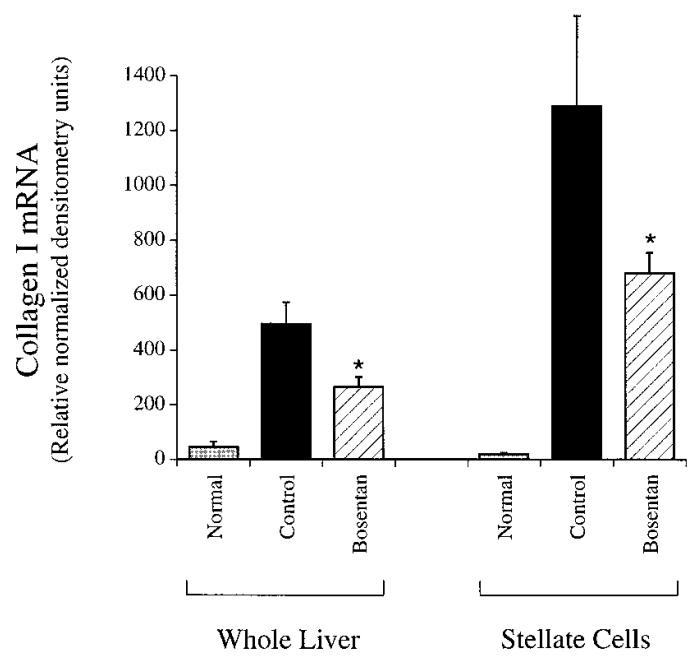

Figure 5. Effect of ET antagonism after established fibrosis on total hepatic and isolated stellate cell type I collagen mRNA. Liver fibrosis was established with carbon tetrachloride (every $5 \mathrm{~d}$ at $0.5 \mathrm{ml} / \mathrm{kg}$, as described in Methods). Bosentan was administered continuously beginning $24 \mathrm{~h}$ after the final (10th) dose of carbon tetrachloride. Control and bosentan-exposed livers were harvested, and cell preparations were performed $17 \mathrm{~d}$ after the final gavage. Total hepatic (10 $\mu \mathrm{g})$ RNA or freshly isolated stellate cell $(5 \mu \mathrm{g})$ RNA was subjected to RNase protection assay with radiolabeled type I collagen and S-14 cRNA, as described in Methods. Specific bands were scanned and normalized to $\mathrm{S}-14$ expression. $* P<0.01$ for the differences between normal and control, as well as control and bosentan for each experimental group, $n=6$ for each group. 


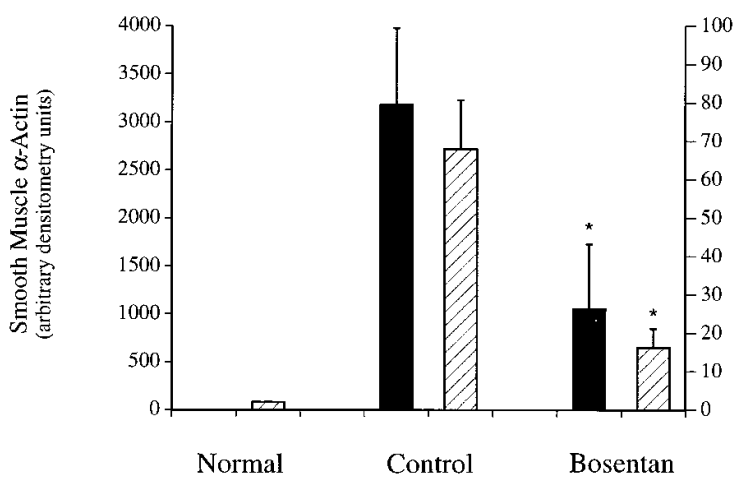

Figure 6. Reduction of stellate cell activation after established liver injury by bosentan. Liver fibrosis was induced and bosentan was administered as described in Fig. 5. Stellate cells were isolated and either immediately lysed (immunoblot) or cultured and immunostained with anti desmin/anti-smooth muscle $\alpha$-actin antibodies. The percentage of cells expressing both desmin and smooth muscle $\alpha$-actin as a proportion of desmin-positive cells is shown. For immunoblots, identical quantities of total protein were separated by PAGE, and immunoblot with anti-smooth muscle $\alpha$-actin antibody was performed as described in Methods. Specific bands for smooth muscle $\alpha$-actin were quantitated. $P<0.001$ for differences between normal and control, and $* P<0.01$ for differences between control and bosentan, $n=$ 6 for each group. $\mathbf{\square}$, smooth muscle $\alpha$-actin (immunoblot); $\square$, smooth muscle $\alpha$-actin (immunocytochemistry).

$43.7 \pm 3.6$ in lobular and expanded portal areas, respectively $(n=$ 4 for each model, both $P<0.05$ for control compared to bosentan). The number of PCNA cells (all areas combined) as a proportion of desmin-positive cells was reduced from $5.92 \pm 0.8 \%$ to $1.7 \pm 0.07 \%$, and $7.33 \pm 0.15 \%$ to $4.7 \pm 1.2 \%$ in the carbon tetrachloride and bile duct ligation models of injury, respectively ( $n=4$ for each model, both $P<0.05$ for control compared to bosentan).

To investigate whether stellate cell activation could be inhibited in vivo after liver injury had been established, we antagonized ET in vivo after the induction of fibrosis. In these experiments, carbon tetrachloride was administered 10 times, and bosentan was instituted $24 \mathrm{~h}$ after the final dose of carbon tetrachloride and continued for the next $17 \mathrm{~d}$. In control livers, central-central, central-portal, and portal-portal bridging was extensive. After ET antagonism, bridging was present, but was less prominent. Quantitative analysis demonstrated a reduction in whole-liver collagen content by 58 and $62 \%$ (Table III) in the central and portal areas, respectively. Whole-liver type I collagen mRNA expression was similarly reduced (Fig. 5). Likewise, in freshly isolated stellate cells, type I collagen mRNA was reduced (Fig. 5). Smooth muscle $\alpha$-actin, assessed by immunoblot and cell counting, was also reduced, confirming the inhibitory effects of bosentan on stellate cell activation (Fig. 6). Finally, in pure cultures of isolated cells that were immunostained $24 \mathrm{~h}$ after isolation, bosentan reduced PCNA labeling from $40.5 \pm 10.6 \%$ to $17.9 \pm 7.5 \%$ of cells.

\section{Discussion}

The wound-healing response is complex and involves interplay between multiple components, including the extracellular matrix, cytokines, and specific cellular elements $(1,2)$. In the liver, stellate cells appear to be responsible in large part for fibro- genesis that accompanies injury. Thus, factors that are capable of stimulating or inhibiting this process are of paramount importance. TGF- $\beta$, PDGF, and certain constituents of the extracellular matrix, such as EIII-A fibronectin, stimulate stellate cell activation and/or fibrogenesis $(2,23,27)$. In contrast, IFN- $\gamma$ and certain basement membrane-like matrices are inhibitory $(21,28)$. Here, we demonstrate that ET is another factor involved in stellate cell activation, as indicated by its effect on smooth muscle $\alpha$-actin in cultured stellate cells and by the inhibitory effect of bosentan in vivo during liver injury. The culture data suggest that bosentan has direct effects at this level. By their nature, however, culture models exclude complex interactions and, therefore, we are unable to rule out additional indirect effects of bosentan in vivo. For example, ET-1 stimulates production of PDGF in human mesangial cells (29), and the possibility that bosentan prevented such downstream events in the hepatic injury response remains open.

Recent data indicate that ET-1 levels are increased during liver injury $(18,19)$. PreproET-1 mRNA and immunoreactive ET-1 in the liver is derived from stellate and endothelial cells, and preproET-1 mRNA appears to be increased in both cell types after injury (19). Therefore, in the context of previous data that demonstrate that ET receptors are markedly more abundant on stellate cells than on hepatocytes, endothelial cells, and Kupffer cells (14), the current results suggest that bosentan inhibited paracrine and/or autocrine effects of ETs on stellate cell activation in vivo.

Our findings emphasize the multifactorial nature of stellate cell activation during injury. While ET antagonism inhibited this process, it did not abolish it, underscoring the concept that non-ET-mediated mechanisms are also important in stellate cell activation. For example, TGF- $\beta$, a cytokine that stimulates stellate cell activation, is upregulated in both models of injury that we examined $(30,31)$. Available evidence indicates that ET does not modulate TGF- $\beta$ directly, thus, ET antagonists might not be expected to influence TGF- $\beta$-mediated events. In support of this concept, we found that ET antagonism before and during the induction of cholestatic induced injury did not alter stellate cell TGF- $\beta 1$ mRNA levels (data not shown). In contrast, in the carbon tetrachloride model, TGF- $\beta 1$ mRNA expression in stellate cells was reduced by 1.9-fold (data not shown). Such data raise the possibility that ET could directly influence TGF- $\beta 1$ mRNA expression. Alternatively, since TGF- $\beta$ expression is part of the stellate cell activation cascade, ET might influence early activation events. Collectively, the data point to complex autocrine (and paracrine) interplay between TGF- $\beta 1$ and ET, and raise the likelihood of differential effects of endothelin in different models of liver injury (i.e., stellate cell activation was inhibited to a relatively greater degree in the carbon tetrachloride model than in the cholestatic model). Finally, we cannot exclude the interaction(s) of ETs and of other components involved in the wounding response, such as extracellular matrix and/or other cytokines.

We demonstrate that stellate cell proliferation during liver injury was inhibited by antagonism of ET in vivo. These data are interesting in view of recent work by Mallat and co-workers, who found that ET-1 inhibited serum-induced human hepatic myofibroblast-like cell proliferation (32). While other studies have indicated that ET-1 is a potent mitogen $(33,34)$, the data in human hepatic myofibroblast-like cells suggests that ET-1 may serve as a potential counterregulatory, antiprolifera- 
tive element in liver fibrogenesis. Since the cells used in these experiments were highly activated myofibroblastic cells, the implication is that these cell types are reflective of those present in advanced fibrotic lesions. We have previously demonstrated, however, that ET-1 has variable (i.e., stimulatory or inhibitory) effects in primary cultures of rat stellate cells (19). In the current experiments, we found that administration of bosentan to animals either before or after established stellate cell activation had antiproliferative effects. In context of the previous data with human myofibroblast-like cells, the evidence suggests either that differences exist in the effects of ET in cultured cells and in in vivo systems, or that there are inherent differences in the effects of ET on human and rat stellate cells.

Antagonism of ET in animals with established stellate cell activation and fibrogenesis reduced stellate cell activation and extracellular matrix mRNA expression. This effect is consistent with the continued expression of ET receptors after stellate cell activation (14). While the data suggest that bosentan directly blocked stellate cell activation and matrix production (allowing reparitive mechanisms to intervene), we cannot exclude the possibility that antagonism of ET has positive effects on matrix degradation and remodeling, presumably at the level of the stellate cell. Additionally, these data have important practical therapeutic implications because the majority of patients present for care with established injury/fibrosis rather than before the onset of liver injury.

The current data are relevant to the pathogenesis of wound healing in general because chronic injury in many organs results in recruitment of matrix-producing cells, such as stellate cells and mesangial cells (as well as fibroblasts/myofibroblasts), matrixproducing cells that likely originate from resident mesenchymal cells $(2,35-38)$. Wounding also leads to upregulation of ET in various forms of organ injury $(18,39,40)$, and ET-1 antibodies block wound contraction in healing skin, suggesting that endogenous ET-1 within the wound modulates the contractile effects of myofibroblasts (38). Collectively, the data suggest that ETs, acting via paracrine and/or autocrine routes, are involved in activation (in addition to contraction) of effector cells in parenchymal injury. Further support for this postulate comes from the identification of ET receptors on candidate target cells, including the stellate cell in the the liver (14), mesangial cells (41) in the kidney, and cardiac fibroblasts (42) in the heart. Whether antagonism of the effect of ET at such a level leads to modulation of the wound-healing response and clinical therapeutic benefit is open to speculation, but merits consideration.

\section{Acknowledgments}

We thank Dr. M. Clozel (F. Hoffman-La Roche, Basel, Switzerland) for supplying bosentan, Dr. David Sanin for use of the IMAGE 1 system, and Dr. D.M. Bissell for review of the manuscript.

This work was supported by the American Liver Foundation and the National Institutes of Health (DK 02124 and DK 50574 to D.C. Rockey; DK 26743 to the University of California at San Francisco Liver Center).

\section{References}

1. Bissell, D.M. 1990. Connective tissue metabolism and hepatic fibrosis: an overview. Sem. Liver Dis. 10:iii-iiv.

2. Friedman, S.L. 1993. Seminars in medicine of the Beth Israel Hospital, Boston. The cellular basis of hepatic fibrosis. Mechanisms and treatment strategies. N. Engl. J. Med. 328:1828-1835.

3. Rockey, D.C., J.K. Boyles, G. Gabbiani, and S.L. Friedman. 1992. Rat hepatic lipocytes express smooth muscle actin upon activation in vivo and in culture. J. Submicrosc. Cytol. Pathol. 24:193-203.

4. Yanagisawa, M., H. Kurihara, S. Kimura, Y. Tomobe, M. Kobayashi, Y. Mitsui, Y. Yazaki, K. Goto, and T. Masaki. 1988. A novel potent vasoconstrictor peptide produced by vascular endothelial cells [see comments]. Nature (Lond.). 332:411-415.

5. Luscher, T.F. 1991. Endothelin. J. Cardiovasc. Pharmacol. 18 (Suppl. 10): S15-S22.

6. Goto, K., and T.D. Warner. 1995. Molecular pharmacology. Endothelin versatility. Nature (Lond.). 375:539-540.

7. Baynash, A.G., K. Hosoda, A. Giaid, J.A. Richardson, N. Emoto, R.E. Hammer, and M. Yanagisawa. 1994. Interaction of endothelin-3 with endothelin-B receptor is essential for development of epidermal melanocytes and enteric neurons. Cell. 79:1277-1285.

8. Clozel, M., V. Breu, G.A. Gray, B. Kalina, B.M. Loffler, K. Burri, J.M. Cassal, G. Hirth, M. Muller, and W. Neidhart. 1994. Pharmacological characterization of bosentan, a new potent orally active nonpeptide endothelin receptor antagonist. J. Pharmacol. Exp. Ther. 270:228-235.

9. Ohlstein, E.H., P. Nambi, S.A. Douglas, R.M. Edwards, M. Gellai, A. Lago, J.D. Leber, R.D. Cousins, A. Gao, and J.S. Frazee. 1994. SB 209670, a rationally designed potent nonpeptide endothelin receptor antagonist. Proc. Natl. Acad. Sci. USA. 91:8052-8056.

10. Gandhi, C.R., K. Stephenson, and M.S. Olson. 1990. Endothelin, a potent peptide agonist in the liver. J. Biol. Chem. 265:17432-17435.

11. Gandhi, C.R., R.H. Behal, S.A. Harvey, T.A. Nouchi, and M.S. Olson. 1992. Hepatic effects of endothelin. Receptor characterization and endothelininduced signal transduction in hepatocytes. Biochem. J. 287:897-904.

12. Stephenson, K., S.A. Harvey, S.B. Mustafa, A.T. Eakes, and M.S. Olson. 1995. Endothelin association with the cultured rat Kupffer cell: characterization and regulation. Hepatology. 22:896-905.

13. Jouneaux, C., A. Mallat, C. Serradeil-Le Gal, P. Goldsmith, J. Hanoune, and S. Lotersztajn. 1994. Coupling of endothelin B receptors to the calcium pump and phospholipase C via Gs and Gq in rat liver. J. Biol. Chem. 269:18451851 .

14. Housset, C., D.C. Rockey, and D.M. Bissell. 1993. Endothelin receptors in rat liver: lipocytes as a contractile target for endothelin 1. Proc. Natl. Acad. Sci. USA. 90:9266-9270.

15. Rockey, D.C. 1995. Characterization of endothelin receptors mediating rat hepatic stellate cell contraction. Biochem. Biophys. Res. Commun. 207:725731.

16. Rockey, D.C., C.N. Housset, and S.L. Friedman. 1993. Activation-dependent contractility of rat hepatic lipocytes in culture and in vivo. J. Clin. Invest. 92:1795-1804

17. Moore, K., J. Wendon, M. Frazer, J. Karani, R. Williams, and K. Badr. 1992. Plasma endothelin immunoreactivity in liver disease and the hepatorenal syndrome. N. Engl. J. Med. 327:1774-1778.

18. Leivas, A., W. Jimenez, S. Lamas, M. Bosch-Marce, J. Oriola, J. Claria, V. Arroyo, F. Rivera, and J. Rodes. 1995. Endothelin 1 does not play a major role in the homeostasis of arterial pressure in cirrhotic rats with ascites. Gastroenterology. 108:1842-1848.

19. Housset, C., A. Laudat, J.J. Chung, and D.C. Rockey. 1995. Expression and potential role of endothelin in cholestatic liver injury. Hepatology. 22:278.

20. Kountouras, J., B.H. Billing, and P.J. Scheuer. 1984. Prolonged bile duct obstruction: a new experimental model for cirrhosis in the rat. Br. J. Exp. Pathol. 65:305-311.

21. de Leeuw, A.M., S.P. McCarthy, A. Geerts, and D.L. Knook. 1984. Purified rat liver fat-storing cells in culture divide and contain collagen. Hepatology. 4:392-403.

22. Chomczynski, P., and N. Sacchi. 1987. Single-step method of RNA isolation by acid guanidinium thiocyanate-phenol-chloroform extraction. Anal. Biochem. 162:156-159.

23. Jarnagin, W.R., D.C. Rockey, V.E. Koteliansky, S.S. Wang, and D.M. Bissell. 1995. Expression of variant fibronectins in wound healing. J. Cell Biol. 127:2037-2048.

24. Maher, J.J., and R.F. McGuire. 1990. Extracellular matrix gene expression increases preferentially in rat lipocytes and sinusoidal endothelial cells during hepatic fibrosis in vivo. J. Clin. Invest. 86:1641-1648.

25. Melton, D.A., P.A. Krieg, M.R. Rebagliati, T. Maniatis, K. Zinn, and M.R. Green. 1984. Efficient in vitro synthesis of biologically active RNA and RNA hybridization probes from plasmids containing a bacteriophage SP6 promoter. Nucleic Acids Res. 12:7035-7056.

26. Malkusch, W., B. Rehn, and J. Bruch. 1995. Advantages of Sirius Red staining for quantitative morphometric collagen measurements in lungs. Exp. Lung Res. 21:67-77.

27. Matsuoka, M., N.T. Pham, and H. Tsukamoto. 1989. Differential effects of interleukin-1 alpha, tumor necrosis factor alpha, and transforming growth factor beta 1 on cell proliferation and collagen formation by cultured fat-storing cells. Liver. 9:71-78.

28. Friedman, S.L., F.J. Roll, J. Boyles, D.M. Arenson, and D.M. Bissell. 1989. Maintenance of differentiated phenotype of cultured rat hepatic lipocytes by basement membrane matrix. J. Biol. Chem. 264:10756-10762.

29. Jaffer, F.E., T.C. Knauss, E. Poptic, and H.E. Abboud. 1990. Endothelin 
stimulates PDGF secretion in cultured human mesangial cells. Kidney. Int. 38: 1193-1198.

30. Nakatsukasa, H., P. Nagy, R.P. Evarts, C.C. Hsia, E. Marsden, and S.S. Thorgeirsson. 1990. Cellular distribution of transforming growth factor-beta 1 and procollagen types I, III, and IV transcripts in carbon tetrachloride-induced rat liver fibrosis. J. Clin. Invest. 85:1833-1843.

31. Saperstein, L.A., R.L. Jirtle, M. Farouk, H.J. Thompson, K.S. Chung, and W.C. Meyers. 1994. Transforming growth factor-beta 1 and mannose 6-phosphate/insulin-like growth factor-II receptor expression during intrahepatic bile duct hyperplasia and biliary fibrosis in the rat. Hepatology. 19:412-417.

32. Mallat, A., L. Fouassier, A.M. Preaux, C.S. Gal, D. Raufaste, J. Rosenbaum, D. Dhumeaux, C. Jouneaux, P. Mavier, and S. Lotersztajn. 1995. Growth inhibitory properties of endothelin-1 in human hepatic myofibroblastic Ito cells. An endothelin B receptor-mediated pathway. J. Clin. Invest. 96:42-49.

33. Battistini, B., P. Chailler, P. D'Orleans-Juste, N. Briere, and P. Sirois. 1993. Growth regulatory properties of endothelins. Peptides. 14:385-399.

34. Fujitani, Y., H. Ninomiya, T. Okada, Y. Urade, and T. Masaki. 1995. Suppression of endothelin-1-induced mitogenic responses of human aortic smooth muscle cells by interleukin-1 beta. J. Clin. Invest. 95:2474-2482.

35. Gabbiani, G., G.B. Ryan, and G. Majne. 1971. Presence of modified fibroblasts in granulation tissue and their possible role in wound contraction. Experientia. 27:549-550.
36. Kuhn, C., and J.A. McDonald. 1991. The roles of the myofibroblast in idiopathic pulmonary fibrosis. Ultrastructural and immunohistochemical features of sites of active extracellular matrix synthesis. Am. J. Pathol. 138:1257-1265.

37. Sappino, A.P., W. Schurch, and G. Gabbiani. 1990. Differentiation repertoire of fibroblastic cells: expression of cytoskeletal proteins as marker of phenotypic modulations. Lab. Invest. 63:144-161.

38. Appleton, I., A. Tomlinson, C.L. Chander, and D.A. Willoughby. 1992. Effect of endothelin-1 on croton oil-induced granulation tissue in the rat. A pharmacologic and immunohistochemical study. Lab. Invest. 67:703-710.

39. Giaid, A., R.P. Michel, D.J. Stewart, M. Sheppard, B. Corrin, and Q. Hamid. 1993. Expression of endothelin-1 in lungs of patients with cryptogenic fibrosing alveolitis. Lancet. 341:1550-1554.

40. Giaid, A., D. Saleh, M. Yanagisawa, and R.D. Forbes. 1995. Endothelin-1 immunoreactivity and mRNA in the transplanted human heart. Transplantation (Baltimore). 59:1308-1313.

41. Simonson, M.S., and W.H. Herman. 1993. Protein kinase C and protein tyrosine kinase activity contribute to mitogenic signaling by endothelin-1. Cross-talk between $\mathrm{G}$ protein-coupled receptors and pp60c-src. J. Biol. Chem. 268:9347-9357.

42. Katwa, L.C., E. Guarda, and K.T. Weber. 1993. Endothelin receptors in cultured adult rat cardiac fibroblasts. Cardiovasc. Res. 27:2125-2129. 